\title{
Genetic and Biochemical Studies of Mutants of Penicillium chrysogenum Impaired in Penicillin Production
}

\author{
By PAMELA J. M. NORMANSELL, I. D. NORMANSELL* AND \\ G. HOLT \\ Life Sciences, The Polytechnic of Central London, New Cavendish Street, \\ London $W 1 M 8 J S$
}

(Received 11 August 1978)

\begin{abstract}
Seventy-eight mutants of Penicillium chrysogenum strain NRRL 1951, that were impaired in penicillin production, were isolated following treatment with various mutagens. Twelve that yielded about $10 \%$ of their parental penicillin titre were studied in detail. Analyses of heterozygous diploids formed between them revealed the existence of at least five complementation groups with respect to penicillin production $-\mathrm{V}, \mathrm{W}, \mathrm{X}, \mathrm{Y}$ and $\mathrm{Z}$. Most mutants belonged to group $\mathrm{Y}$. A biochemical investigation of the intracellular peptides in strains representing the five groups demonstrated the absence of the tripeptide $\alpha$-aminoadipoylcysteinyl-valine from mutants of groups $\mathrm{X}, \mathrm{Y}$ and $\mathrm{Z}$. Extracts of mutants of groups W, Y and $\mathrm{Z}$ were able to catalyse a penicillin acyl-exchange reaction, a mutant of group $\mathrm{V}$ showed only a trace of activity and a mutant from group $\mathrm{X}$ completely lacked this ability.
\end{abstract}

\section{INTRODUCTION}

Caglioti \& Sermonti (1956) and Sermonti (1956) isolated mutants of Penicillium chrysogenum impaired in penicillin production. Complementation analysis with heterozygous diploids established the existence of two genetic loci. More recently, investigations of the genetics of penicillin production have been carried out in Aspergillus nidulans (Macdonald \& Holt, 1976), and using mutants of this mould Edwards et al. (1974) showed the presence of four genetic loci affecting penicillin synthesis.

An elegant biochemical investigation of impaired mutants of $P$. chrysogenum by Nash et al. (1974) established clear differences in their ability to synthesize possible intermediates in the penicillin pathway. Similar studies with mutants of Acremonium chrysogenum having no detectable cephalosporin $\mathrm{C}$ activity demonstrated the existence of two types of mutants, with or without the ability to elaborate the postulated intermediate $\alpha$-aminoadipoylcysteinyl-valine (Lemke \& Nash, 1972). Fujisawa et al. $(1973,1975 a, b)$ were able to separate cephalosporin $\mathrm{C}$ negative mutants into two biochemically distinct groups, both involved in the final steps of cephalosporin $\mathbf{C}$ biosynthesis.

The work described in this paper combined a genetic study of mutants of $P$. chrysogenum impaired in penicillin production with biochemical investigations concerning the effect on the penicillin biosynthetic pathway of the altered genetic loci.

* Present address: Beecham Pharmaceuticals, Clarendon Road, Worthing, West Sussex BN14 8QH. 


\section{METHODS}

Abbreviations. ACV-tripeptide, $\alpha$-aminoadipoyl-cysteinyl-valine; $\mathrm{ACV}-\mathrm{SO}_{3} \mathrm{H}, \alpha$-aminoadipoyl-cysteoylvaline (product by performic acid oxidation of ACV-tripeptide).

Strains. Mutant derivatives of the wild-type strain of Penicillium chrysogenum NRRL 1951 (Raper \& Alexander, 1945) were used. Strain NRRL 1951 yields about $30 \mu \mathrm{g}$ penicillin $\mathrm{ml}^{-1}$. Another strain derived from NRRL 1951 after several sequential mutagenic treatments, designated WIS54-1255 (Backus \& Stauffer, 1955 ) and capable of synthesizing about $1800 \mu \mathrm{g}$ penicillin $\mathrm{ml}^{-1}$, was also employed.

Media. Minimal medium and complete medium were based on those described by Pontecorvo et al. (1953). The medium for penicillin production (FM) was that used by Holt \& Macdonald (1968). The chemically defined medium for penicillin production (CDMP) was described by Hockenhull (1959). Incubation was at $25^{\circ} \mathrm{C}$ throughout.

Mutagenesis. The mutagens used for the production of auxotrophic and spore colour mutants and mutants impaired in penicillin production were far ultraviolet light at $254 \mathrm{~nm}$ (FUV), or near ultraviolet light at $365 \mathrm{~nm}$ after sensitization with 8-methoxypsoralen (8MOP/NUV). The procedures were those described by Macdonald et al. (1963a) and Alderson \& Scott (1970). Mutants impaired in antibiotic production were also isolated after treatment with ethyl methanesulphonate (EMS) (Yost et al., 1967).

Isolation of mutants impaired in penicillin production. Following treatment to $1 \%$ survival with FUV or $8 \mathrm{MOP} / \mathrm{NUV}$, or to $50 \%$ survival with EMS, individual colonies were sampled and their penicillin productivity tested by the rapid screening procedure described by Edwards et al. (1974). Strains producing significantly less penicillin than their parents were then grown in submerged culture using $100 \mathrm{ml}$ shake flasks containing $18 \mathrm{ml} \mathrm{FM}$, incubated at $25^{\circ} \mathrm{C}$ on an orbital shaker with a $5 \mathrm{~cm}$ throw at $220 \mathrm{rev}$. $\mathrm{min}^{-1}$. After $5 \mathrm{~d}$ the broths were filtered and assayed using the agar-well diffusion technique, with Bacillus subtilis NCTC 8236 as the test organism, and the penicillin yields of the mutants were established accurately (Brownlee et al., 1949). Those with about $10 \%$ or less of the antibiotic-producing activity of their parents were designated Npe mutants.

Isolation of heterozygous diploids. Heterozygous diploids were normally synthesized between strains carrying complementary auxotrophic and spore colour mutations, using methods based on those of Macdonald et al. $(1963 \mathrm{~b})$. Diploidy was confirmed by measurement of conidial diameters and haploidization of putative diploids with a benzimidazole fungicide (Edwards et al., 1975).

Complementation analysis.

(i) Co-synthesis. Pairs of Npe strains were tested for co-synthesis of penicillin by growing them together in submerged, shaken cultures of FM.

(ii) Heterozygous diploids. All heterozygous diploids synthesized between complementary Npe mutants were assayed for penicillin yield in shake flask cultures, mostly in quadruplicate.

Examination of intracellular peptides by two-dimensional chromatography.

(i) Extraction of intracellular peptides. Intracellular peptides were extracted by a method based on that of Arnstein et al. (1960). Individual strains were grown in $16250 \mathrm{ml}$ shake flasks, each containing $50 \mathrm{ml} \mathrm{FM}$, for $4 \mathrm{~d}$. The mycelium from all the flasks was then combined to give a damp-dry weight of between 150 and $200 \mathrm{~g}$ and extracted three times with boiling aqueous ethanol. After centrifugation, the supernatant was reduced in volume and desalted on an Amberlite IR-220 $\left(\mathrm{H}^{+}\right.$form) column. The eluate was then freeze-dried.

(ii) Performic acid oxidation. Samples $(100 \mathrm{mg})$ of the freeze-dried residues were dissolved in $0.2 \mathrm{ml}$ $98 \%(\mathrm{w} / \mathrm{v})$ formic acid and cooled in an ice-bath; $0.2 \mathrm{ml} \mathrm{3 \%}(\mathrm{w} / \mathrm{v})$ performic acid $[9 \mathrm{ml} 98 \%(\mathrm{w} / \mathrm{v})$ formic acid and $1.0 \mathrm{ml} 30 \%$ hydrogen peroxide left at room temperature for $2 \mathrm{~h}$ ] was then added and the solution was left at $4{ }^{\circ} \mathrm{C}$ for $5 \mathrm{~h}$. Then $10 \mathrm{vol}$. distilled water were added and the mixture was freeze-dried.

(iii) Electrophoresis and paper chromatography. Two-dimensional separations were performed on Whatman no. 1 paper using $7.5 \mathrm{mg}$ of the performic acid-oxidized sample. Electrophoresis was carried out in $\mathrm{pH} 1.8$ buffer [20\%(w/v) acetic acid containing $2 \%(\mathrm{w} / \mathrm{v})$ formic acid] at $70 \mathrm{~V} \mathrm{~cm}^{-1}$ as described by Smith et al. (1967) on an apparatus similar to that of Katz et al. (1959). Paper chromatograms were run in butan-1-ol/acetic acid/water ( $4: 1: 4$, by vol.) at room temperature for $18 \mathrm{~h}$. Standards used were glutathione

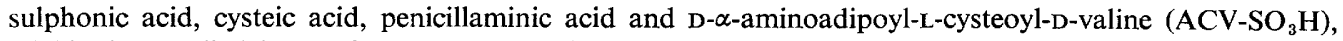
all kindly supplied by Professor E. P. Abraham (Sir William Dunn School of Pathology, University of Oxford). The chromatograms were visualized using a cadmium-ninhydrin reagent (Heilmann et al., 1957).

(iv) Concentration of the sulphonic acids. When electrophoretic separation proved unsatisfactory due to a high concentration of non-performic acid oxidized material in the sample, a simple purification step was employed: $30 \mathrm{mg}$ sample dissolved in $100 \mathrm{ml}$ water was loaded on to a column $(3 \times 1 \mathrm{~cm})$ of Dowex 50-X4 $\left(\mathrm{H}^{+}\right.$form) and then eluted with water. The sulphonic acids were released in the first $6 \mathrm{ml}$ of eluate, achieving a 10 -fold purification. 
Labelling of the $A C V$-tripeptide with $\mathrm{L}-\left[U-{ }^{14} C\right]$ valine.

(i) Extraction of intracellular peptides. Mycelium grown in $50 \mathrm{ml}$ of the chemically defined medium CDMP (without side-chain precursor) was washed three times in distilled water by resuspension and filtering, and then pressed dry between sheets of filter paper. A portion $(2 \mathrm{~g})$ of this mycelium was added to $38 \mathrm{ml}$ of water in a $250 \mathrm{ml}$ flask containing $5 \mu \mathrm{Ci} \mathrm{L}-\left[\mathrm{U}-{ }^{14} \mathrm{C}\right]$ valine $\left(270 \mathrm{mCi} \mathrm{mmol}^{-1}\right.$; The Radiochemical Centre, Amersham) and incubated at $27^{\circ} \mathrm{C}$ on an orbital shaker at $160 \mathrm{rev}$. $\mathrm{min}^{-1}$. Samples $(0 \cdot 25 \mathrm{ml})$ were taken after $1,2,5,10$ and $20 \mathrm{~min}$, centrifuged briefly and $10 \mu \mathrm{l}$ of the supernatant was removed for scintillation counting. When approximately $80 \%$ of the activity had been removed from the extracellular medium the contents of the flask were harvested by centrifuging at $3000 \mathrm{~g}$ for $10 \mathrm{~min}$. The mycelial pellet was extracted by stirring with ice-cold $70 \%$ aqueous acetone in an ice bath for $15 \mathrm{~min}$. The pellet was centrifuged as before for $10 \mathrm{~min}$ and the supernatant was subjected to rotary evaporation to remove the acetone prior to freeze drying.

(ii) Electrophoresis and paper chromatography. Two-dimensional separations were performed on Whatman no. 1 paper using $2.0 \mathrm{mg}$ sample. Electrophoresis was carried out in $\mathrm{pH} 4.5$ buffer (pyridine/glacial acetic acid/water; 5:7.5:2480, by vol.) at $70 \mathrm{~V} \mathrm{~cm}^{-1}$ for $35 \mathrm{~min}$. Paper chromatograms were run in the 'Lilly system' (propan-1-ol-/pyridine/acetic acid/acetonitrile/water; 40:30:9:40:36, by vol.; Nash et al., 1974) at $4{ }^{\circ} \mathrm{C}$ for $17 \mathrm{~h}$. After separation, the chromatograms were visualized with ninhydrin reagent; the regions corresponding to ACV-tripeptide and 6-aminopenicillanic acid were cut out and their radioactivity was estimated by scintillation counting.

(iii) Separation of the sulphonic acids. A portion of the intracellular material was dissolved in $120 \mu \mathrm{l}$ water and applied to paper as $12 \times 10 \mu \mathrm{l}$ aliquots. These were run in the 'Lilly system' (Nash et al., 1974) at room temperature for $5 \mathrm{~h}$. The regions corresponding to the ACV-tripeptide, 6-aminopenicillanic acid and penicillin $\mathrm{G}$ were eluted and freeze-dried. The samples were then oxidized with performic acid in the normal way and freeze-dried. Each of these samples was dissolved in $20 \mu \mathrm{l}$ water and applied to paper as $1 \times 5 \mu \mathrm{l}$ and $1 \times 15 \mu 1$ aliquots; penicillaminic acid and $\mathrm{ACV}-\mathrm{SO}_{3} \mathrm{H}$ were included as standards. After electrophoresis at $\mathrm{pH} 1.8,70 \mathrm{~V} \mathrm{~cm}^{-1}$ for $2 \mathrm{~h}$, the standards and the $5 \mu 1$ sample strips were visualized using ninhydrin. The remaining $15 \mu \mathrm{l}$ strips were cut into $1 \mathrm{~cm}$ lengths and the distribution of radioactivity was estimated by scintillation counting.

(iv) Stimulation of the penicillin biosynthetic pathway. To examine whether the addition of $\alpha$-aminoadipic acid could stimulate the production of tripeptide in strains capable of elaborating this compound, preliminary experiments were conducted using a penicillin-producing strain, HP41, and a range of $\alpha$-aminoadipic acid concentrations. These experiments indicated that an approximately threefold improvement in labelling of the ACV-tripeptide could be achieved by preincubating the washed mycelium in a solution containing $0.5 \mathrm{mg} \alpha$-aminoadipic acid $\mathrm{ml}^{-1}$.

Portions $(2 \mathrm{~g})$ of mycelium of mutant strains prepared in the normal way were resuspended in $38 \mathrm{ml}$ water containing $0.5 \mathrm{mg} \alpha$-aminoadipic acid $\mathrm{ml}^{-1}$ and the flasks were shaken at $160 \mathrm{rev} . \mathrm{min}^{-1}$ for $60 \mathrm{~min}$ before adding radioactive valine $(5 \mu \mathrm{Ci})$. Harvesting was carried out after $20 \mathrm{~min}$ and the intracellular material was extracted and examined as described above.

Identification of the ACV-like peptide.

(i) Method A. Intracellular material was obtained from strains grown in FM and oxidized with performic acid as described above. Samples were applied to Whatman no. 1 paper at $3 \mathrm{~cm}$ intervals, each spot containing $2.5 \mathrm{mg}$ in $5 \mu$ l. Electrophoresis was carried out at $70 \mathrm{~V} \mathrm{~cm}^{-1}$ in $\mathrm{pH} 1.8$ buffer for $3 \mathrm{~h}$. Strips were cut from the electrophoretogram corresponding to the two outer and the centre spots, and visualized using cadmium-ninhydrin reagent. The area corresponding to the ACV-complex was cut out, eluted with water, and the eluate ( 1 to $2 \mathrm{ml}$ ) was freeze-dried. The freeze-dried sample was hydrolysed with $6 \mathrm{M}-\mathrm{HCl}$ at $105^{\circ} \mathrm{C}$ for $18 \mathrm{~h}$ in evacuated tubes. After opening, the tubes were placed in a vacuum desiccator. The sample was redissolved in $0.2 \mathrm{ml}$ water and taken down to dryness twice before being analysed for amino acids.

(ii) Method B. Intracellular extracts were obtained after incorporation of radioactive valine as described above. The sample material was applied to Whatman no. 1 paper in $10 \mu \mathrm{l}$ spots containing $1.0 \mathrm{mg}$ extract. Electrophoresis was carried out in $\mathrm{pH} 4.5$ buffer at $70 \mathrm{~V} \mathrm{~cm}^{-1}$ for $35 \mathrm{~min}$. The region corresponding to ACV-tripeptide was eluted and freeze-dried. The material was then subjected to descending chromatography in the 'Lilly system' (Nash et al., 1974) at $4{ }^{\circ} \mathrm{C}$ for $17 \mathrm{~h}$. A sample strip was removed and visualized with cadmium-ninhydrin reagent and the region corresponding to the tripeptide was eluted and freeze-dried. To check the homogeneity of the sample, one-eighth of it was subjected to two-dimensional separation as before. This gave a single discrete ninhydrin-positive spot in the expected position. The remaining material was hydrolysed as described in method A.

(iii) Identification of the amino acids. Samples of the hydrolysate corresponding to one-eighth of the total material were subjected to electrophoretic separation at $\mathrm{pH} 1 \cdot 8,70 \mathrm{~V} \mathrm{~cm}^{-1}$ for $30 \mathrm{~min}$ and at $\mathrm{pH} 4.5,70 \mathrm{~V}$ $\mathrm{cm}^{-1}$ for $45 \mathrm{~min}$. Appropriate amino acid standards were run with the sample. The remaining material was separated in an amino acid analyser. 
Determination of acyl-exchange activity. Individual strains were grown in four $250 \mathrm{ml}$ shake flasks each containing $50 \mathrm{ml}$ FM. After $4 \mathrm{~d}$ the mycelium was washed by filtration, bulked and resuspended in ice-cold buffer, pH $7.8\left(0.2 \mathrm{M}-\mathrm{NaCl}, 0.2 \mathrm{M}\right.$-Tris, $0.05 \mathrm{M}-\mathrm{KH}_{2} \mathrm{PO}_{4}, 0.001 \mathrm{M}$-EDTA) as described by Gatenbeck \& Brunsberg (1968). The mycelium was then pressed dry between sheets of filter paper and ground in an ice-cold pestle and mortar for $10 \mathrm{~min}$ with half its weight of Celite. The paste was ground for a further $5 \mathrm{~min}$ with $5 \mathrm{~mm}$ dithiothreitol in $\mathrm{pH} 7.8$ buffer. The clear, pale yellow supernatant obtained after centrifugation at $4{ }^{\circ} \mathrm{C}$ and $3000 \mathrm{~g}$ for $20 \mathrm{~min}$ was used immediately for estimation of acyl-exchange activity.

The reaction mixture (final volume $6.0 \mathrm{ml}$ ) contained ${ }^{35} \mathrm{~S}$-labelled penicillin $\mathrm{G}\left(500\right.$ units $\mathrm{ml}^{-1}, 0.2 \mu \mathrm{Ci}$ $\mathrm{ml}^{-1}$; kindly supplied by Glaxo Laboratories Ltd, Ulverston), penicillin V (500 units $\mathrm{ml}^{-1}$ ), 6-aminopenicillanic acid $(0.01 \mathrm{~mm})$ and crude enzyme extract $(5.0 \mathrm{ml})$. It was shaken at $220 \mathrm{rev} . \mathrm{min}^{-1}$ at $25^{\circ} \mathrm{C}$. Samples of $10 \mu \mathrm{l}$ were taken at $0,0.5,1.0$ and $4.0 \mathrm{~h}$ and applied in duplicate to Whatman no. 1 paper strips [ $1.5 \mathrm{~cm}$ wide and pre-buffered at $\mathrm{pH} 5.5$ with $10 \%(\mathrm{w} / \mathrm{v})$ potassium citrate buffer]. A drop of Sudan III dissolved in ether was applied to each strip to facilitate visualization of the solvent front. The strips were subjected to descending chromatography at $23{ }^{\circ} \mathrm{C}$ for $2.5 \mathrm{~h}$ in an ether/water system based on that of Brewer \& Johnson (1953). [Preliminary experiments in which the strips were pre-buffered using solutions of $\mathrm{pH} 5 \cdot 0$, $5.5,6.0$ and 6.5 had indicated that $\mathrm{pH} 5.5$ gave optimal separation of penicillin $\mathrm{G}$ and penicillin $\mathrm{V}$ with $R_{F}$ values of approximately 0.45 and 0.65 , respectively.] After drying, one strip of each duplicate pair was placed on the surface of an agar assay plate seeded with Bacillus subtilis and incubated at $37^{\circ} \mathrm{C}$ for 16 to $24 \mathrm{~h}$, when the antibiotic inhibition could be clearly seen. The other strip was cut into $1 \mathrm{~cm}$ lengths and the distribution of radioactivity was determined by liquid scintillation counting.

\section{RESULTS}

\section{Isolation of mutants impaired in penicillin yield}

A total of 78 mutants were isolated which elaborated $50 \%$, or less, of the amount of penicillin produced by their parents. Care was taken to avoid isolating mutants which were morphologically abnormal, had additional auxotrophic requirements or were unable to elaborate the pigment chrysogenin. Twelve of these strains having penicillin yields of about $10 \%$ or less that of their parents were selected for further study; the derivation of these Npe mutants is shown in Table 1.

\section{Complementation of Npe strains}

Co-synthesis. The 12 Npe mutants were co-fermented in all possible pairs. In no case did a mixed growth produce significantly more penicillin than either component strain grown alone.

Heterozygous diploids. Thirty-one diploids were synthesized between different Npe strains and tested for penicillin yield (Table 2). If a heterozygous diploid between two mutants had a penicillin yield close to that of the strains from which the mutants were derived then the mutations were assigned to different genetic loci; but if penicillin production was impaired, indicating non-complementation, both mutations were assigned to the same genetic locus. The penicillin titres of the heterozygous diploids were subject to a degree of biological variation, in addition to normal assay variation (Merrick \& Caten, 1975), which may have been due partly to the production of dominant or semi-dominant mutations impairing penicillin biosynthesis during the diploidization process (Macdonald et al., 1965; Macdonald, 1966). In no instance was complementation inferred when a diploid synthesized less than four times the amount of penicillin of the highest-yielding component haploid. Eleven separate mutations were each assigned to one of four complementation groups: group V, npe-006; group $\mathrm{W}$, npe-0010 npe-0052; group $\mathrm{X}$, npe-0066; group $\mathrm{Y}$, npe-004 npe-0013 npe-0019 npe-0055 npe-0061 npe-0067 npe-0068. Due to the similar genetic background of strains bearing mutations npe-006 and npe-001, it was not possible to test for complementation between them. However, they have been located on separate haploidization groups (I. D. Normansell, G. Holt \& K. D. Macdonald, unpublished data) and thus a fifth complementation group, $\mathrm{Z}$ (represented by npe-001), has been recognized. 
Table 1. Derivation of mutants impaired in penicillin yield

Parent strains

\begin{tabular}{|c|c|c|c|c|}
\hline \multirow[b]{2}{*}{ Strain no. } & \multirow[b]{2}{*}{ Genotype* } & \multirow{2}{*}{$\begin{array}{c}\text { Penicillin } \\
\text { titre } \\
\left(\mu \mathrm{g} \mathrm{ml}^{-1}\right)\end{array}$} & \multicolumn{2}{|l|}{ Mutants } \\
\hline & & & Isolate no. & Mutagen $\dagger$ \\
\hline HP15 & anA004 choA001 & $27 \cdot 0$ & 0066 & FUV \\
\hline HP16 & anA004 ino $A 001$ & $20 \cdot 0$ & $0052,0055,0061$ & $8 \mathrm{MOP} / \mathrm{NUV}$ \\
\hline HP2O & anA004 proA001 & $20 \cdot 0$ & 0067,0068 & EMS \\
\hline HP41 & $\begin{array}{l}\text { anA004 pyro } A 001 \\
\text { bwA005 }\end{array}$ & $30 \cdot 0$ & $001,004,006,0010,0013,0019$ & FUV \\
\hline
\end{tabular}

* Symbols indicate requirements for aneurin (an), choline (cho), inositol (ino), proline (pro) and pyridoxine (pyro), and brown spore colour $(b w)$.

$\dagger$ FUV, far ultraviolet light at $254 \mathrm{~nm} ; 8 \mathrm{MOP} / \mathrm{NUV}, 8$-methoxypsoralen followed by ultraviolet light at $365 \mathrm{~nm}$; EMS, ethyl methanesulphonate.

Table 2. Complementation analysis of Npe mutants by formation of heterozygous diploids Component haploids

\begin{tabular}{|c|c|c|c|c|c|c|c|}
\hline Strain no. & npe no. & $\begin{array}{c}\text { Titre } \\
\left(\mu \mathrm{g} \mathrm{ml}^{-1}\right)\end{array}$ & Strain no. & npe no. & $\begin{array}{c}\text { Titre } \\
\left(\mu \mathrm{g} \mathrm{ml}^{-1}\right)\end{array}$ & $\begin{array}{c}\text { Diploid } \\
\text { titre } \\
\left(\mu \mathrm{g} \mathrm{ml}^{-1}\right)\end{array}$ & $\begin{array}{c}\text { Comple- } \\
\text { mentation* }\end{array}$ \\
\hline HP78 & 001 & 0.0 & HP144 & 0052 & 0.0 & $34 \cdot 2$ & + \\
\hline HP78 & 001 & 0.0 & HP145 & 0055 & $1 \cdot 3$ & 14.4 & + \\
\hline HP78 & 001 & 0.0 & HP147 & 0061 & $1 \cdot 3$ & $20 \cdot 0$ & + \\
\hline HP78 & 001 & 0.0 & HP153 & 0066 & $0 \cdot 0$ & $32 \cdot 7$ & + \\
\hline HP78 & 001 & $0 \cdot 0$ & HP156 & 0067 & 0.0 & $8 \cdot 0$ & + \\
\hline HP81 & 004 & $5 \cdot 3$ & HP144 & 0052 & 0.0 & $19 \cdot 2$ & + \\
\hline HP81 & 004 & $5 \cdot 3$ & HP153 & 0066 & 0.0 & $23 \cdot 4$ & + \\
\hline HP81 & 004 & $5 \cdot 3$ & HP156 & 0067 & $0 \cdot 0$ & $6 \cdot 9$ & - \\
\hline HP83 & 006 & 3.9 & HP144 & 0052 & $0 \cdot 0$ & $24 \cdot 6$ & + \\
\hline HP83 & 006 & 3.9 & HP153 & 0066 & 0.0 & $16 \cdot 8$ & + \\
\hline HP83 & 006 & 3.9 & HP156 & 0067 & 0.0 & $33 \cdot 7$ & + \\
\hline HP87 & 0010 & $1 \cdot 8$ & HP144 & 0052 & 0.0 & $3 \cdot 7$ & - \\
\hline HP87 & 0010 & 1.8 & HP153 & 0066 & 0.0 & $10 \cdot 5$ & + \\
\hline HP87 & 0010 & $1 \cdot 8$ & HP156 & 0067 & 0.0 & $14 \cdot 1$ & + \\
\hline HP90 & 0013 & $0 \cdot 3$ & HP144 & 0052 & 0.0 & $25 \cdot 8$ & + \\
\hline HP90 & 0013 & $0 \cdot 3$ & HP153 & 0066 & 0.0 & $20 \cdot 0$ & + \\
\hline HP90 & 0013 & 0.3 & HP156 & 0067 & 0.0 & 0.8 & - \\
\hline HP96 & 0019 & 0.0 & HP144 & 0052 & 0.0 & $34 \cdot 2$ & + \\
\hline HP96 & 0019 & 0.0 & HP145 & 0055 & $1 \cdot 3$ & $1 \cdot 7$ & - \\
\hline HP96 & 0019 & 0.0 & HP147 & 0061 & $1 \cdot 3$ & $4 \cdot 8$ & - \\
\hline HP96 & 0019 & 0.0 & HP153 & 0066 & 0.0 & $17 \cdot 0$ & + \\
\hline HP96 & 0019 & 0.0 & HP156 & 0067 & 0.0 & 0.0 & - \\
\hline HP96 & 0019 & 0.0 & HP158 & 0068 & $0 \cdot 0$ & $3 \cdot 2$ & - \\
\hline HP144 & 0052 & 0.0 & HP157 & 0067 & 0.0 & 15.0 & + \\
\hline HP144 & 0052 & 0.0 & HP158 & 0068 & 0.0 & $10 \cdot 8$ & + \\
\hline HP145 & 0055 & $1 \cdot 3$ & HP154 & 0066 & $0 \cdot 0$ & $15 \cdot 2$ & + \\
\hline HPI 45 & 0055 & $1 \cdot 3$ & HP157 & 0067 & 0.0 & 0.8 & - \\
\hline HP147 & 0061 & $1 \cdot 3$ & HP154 & 0066 & 0.0 & $8 \cdot 4$ & + \\
\hline HP147 & 0061 & $1 \cdot 3$ & HP157 & 0067 & 0.0 & $0 \cdot 1$ & - \\
\hline HP154 & 0066 & 0.0 & HP156 & 0067 & 0.0 & $14 \cdot 1$ & + \\
\hline HP154 & 0066 & 0.0 & HP158 & 0068 & 0.0 & $16 \cdot 3$ & + \\
\hline
\end{tabular}

$*+$, Occurrence of complementation; - , absence of complementation. 


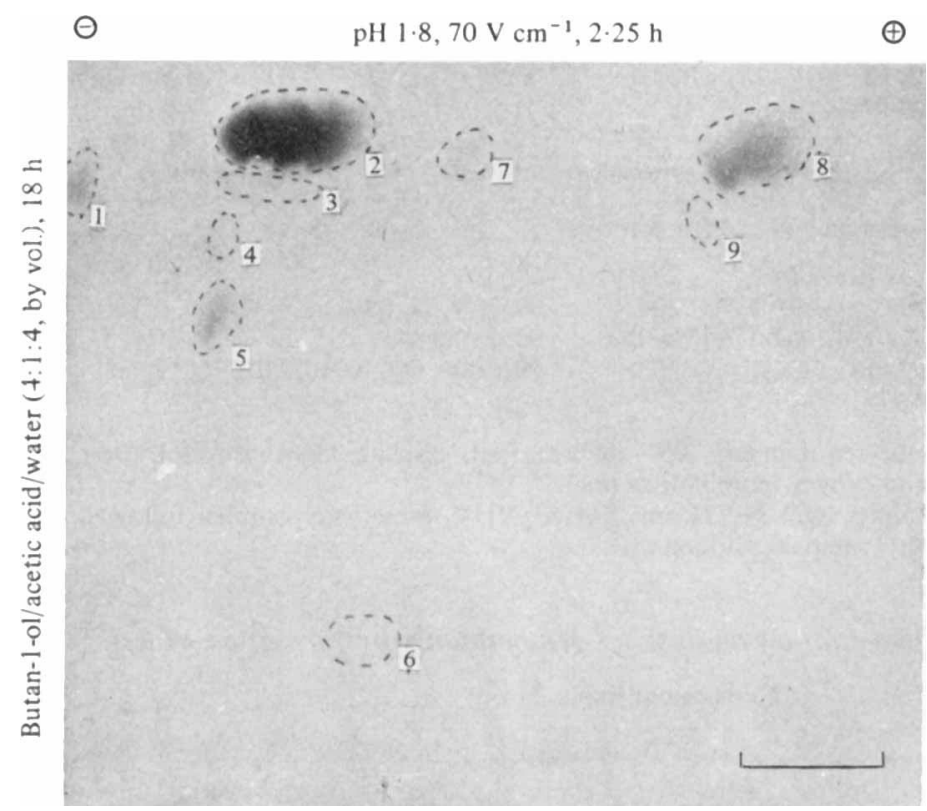

Fig. 1. Analysis of performic acid-oxidized extracts of Penicillium chrysogenum strain HP16 by electrophoresis on paper at $\mathrm{pH} 1.8$ followed by chromatography in the second dimension in butan-1ol/acetic acid/water. The chromatograms were dipped in a cadmium-ninhydrin reagent. Only spots 2 (glutathione sulphonic acid), $5\left(\mathrm{ACV}-\mathrm{SO}_{3} \mathrm{H}\right.$ ), 8 (cysteic acid) and 9 (penicillaminic acid) have been identified by comparison with authentic standards. Bar marker represents $5 \mathrm{~cm}$.

\section{Radial colony growth rate and mycelial dry weight of strains representative of complementation groups}

Measurements of radial colony growth rate demonstrated that mutants from groups $\mathrm{V}$, $\mathrm{W}, \mathrm{X}$ and $\mathrm{Y}$ had similar growth rates to their parents. However, the sole representative of (group Z (npeZ001) had a radial colony growth rate of approximately $50 \%$ that of its parent.

The mycelial dry weights of five strains carrying npe mutations and their parents were measured following growth in triplicate in shake flasks. The results, expressed for each mutant as a percentage of its parent yield, were as follows: npeV006 $(90 \cdot 3 \pm 11 \cdot 2)$, npeW0052 $110 \cdot 0 \pm 13 \cdot 1)$, npeX0066 (66.0 $\pm 4 \cdot 6)$, npeY0019 (113.5 $\pm 8 \cdot 5)$ and npeZ001 $(96 \cdot 3 \pm 6 \cdot 4)$.

\section{Dominance tests with npe mutations}

In tests of dominance, the eight npe mutations tested $(001,006,0010,0019,0052,0066$, 0067 and 0068), which included representatives of all five complementation groups, were found to be recessive.

\section{Examination of intracellular peptides by two-dimensional chromatography}

A typical two-dimensional chromatogram from strain HP16 is shown in Fig. 1; the identity of a number of ninhydrin-positive spots was inferred by comparison with authentic samples. When strains producing ACV-tripeptide were mixed with the standard $\mathrm{ACV}-\mathrm{SO}_{3} \mathrm{H}$ prior to separation, only a single spot of $\mathrm{ACV}-\mathrm{SO}_{3} \mathrm{H}$ (Fig. 1, spot 5) was detected after separation. The four parent strains - HP15, HP16, HP20 and HP41 - and mutants representative of the five complementation groups - HP83 (npeV006), HP129 (npeW0052), HP149 (npeX0066), HP150 (npeY0067) and HP78 (npeZ001) - were analysed for the presence of intracellular ACV. Tripeptide was found in all parent strains and in Npe 
Table 3. Radioactivity present in the 'ACV-tripeptide' from Npe strains after two-dimensional chromatography

$\begin{array}{ccc}\text { Strain no. } & \begin{array}{c}\text { npe } \\ \text { mutation }\end{array} & \begin{array}{c}\text { Radioactivity } \\ \text { (c.p.m.) in } \\ \text { 'ACV-tripeptide'* }\end{array} \\ \text { HP41 } & - & 1601 \\ \text { HP78 } & \text { Z001 } & \text { Not tested } \\ \text { HP150 } & \text { Y0067 } & 731 \\ \text { HP149 } & \text { X0066 } & 336 \\ \text { HP129 } & \text { W0052 } & 4134 \\ \text { HP83 } & \text { V006 } & 1482\end{array}$

* Radioactivities have been adjusted to represent the activities in the total extract.

mutants representing complementation groups $\mathrm{V}$ and $\mathrm{W}$, but not in mutants from groups $\mathrm{X}$, $\mathrm{Y}$ and $\mathrm{Z}$. Penicillaminic acid (possibly derived from penicillin $\mathrm{G}, 6$-aminopenicillanic acid or isopenicillin $\mathrm{N}$ ) was detected in all the parent strains tested and also in mutant HP83.

\section{Labelling of the $A C V$-tripeptide with $\mathrm{L}-\left[U-{ }^{14} C\right]$ valine}

Electrophoresis and paper chromatography. At the loading used, ninhydrin-positive material was detected in the region corresponding to the ACV-tripeptide only in extracts from strain HP129 (npeW0052); however, the appropriate area of the chromatogram was removed in experiments with all mutants and subjected to scintillation counting. Typical results are shown in Table 3. The incorporation of ${ }^{14} \mathrm{C}$ into the $\mathrm{ACV}$-tripeptide produced by mutant HP129 was consistently about 2.5 times higher than the incorporation achieved by wild-type strains. The representative of group $\mathrm{V}$ responded similarly to the wild-type strain HP41, whereas representatives of groups $\mathrm{Y}$ and $\mathrm{X}$ incorporated considerably less radioactivity.

Separation of the sulphonic acids. The intracellular extracts of selected strains were oxidized with performic acid and subjected to electrophoretic separation. Although the radioactivities were fairly low, the electrophoretograms for the two wild-type strains tested (HP16 and HP41) and representatives of groups V and W (HP83 and HP129) indicated significant incorporation of ${ }^{14} \mathrm{C}$ in the region corresponding to $\mathrm{ACV}-\mathrm{SO}_{3} \mathrm{H}$. A mutant of group $\mathrm{Y}$ (HP96), however, showed no such incorporation. A more detailed investigation was conducted on strains treated with $\alpha$-aminoadipic acid before incorporation of radioactive valine.

Stimulation of the penicillin biosynthetic pathway. Only three strains were used in this experiment: HP41 (a wild-type penicillin producer), and mutants HP83 (npeV006) and HP129 (npeW0052); the two mutants had previously been shown to produce tripeptide-like material. The radioactivity profiles are shown in Fig. 2 and the results are summarized in Table 4. It can be seen that the incorporation of ${ }^{14} \mathrm{C}$ into the $\mathrm{ACV}$-tripeptide was highest in strain HP129, giving a level of radioactivity more than twice that of the wild-type and more than three times that of strain HP83. No labelled 6-aminopenicillanic acid was produced by strain HP129.

\section{Identification of the ACV-like peptide}

All analyses showed trace amounts of serine, threonine and aspartic acid, but these were not thought to be significant.

Method $A$. Elution of the area corresponding to the tripeptide, following electrophoresis of an extract of strain HP41, showed the presence, after hydrolysis, of the amino acids cysteic acid, glycine, $\alpha$-aminoadipic acid and valine, the last two being in the molar ratio $1: 1$. However, since only one-dimensional chromatography was used, the region corresponding 


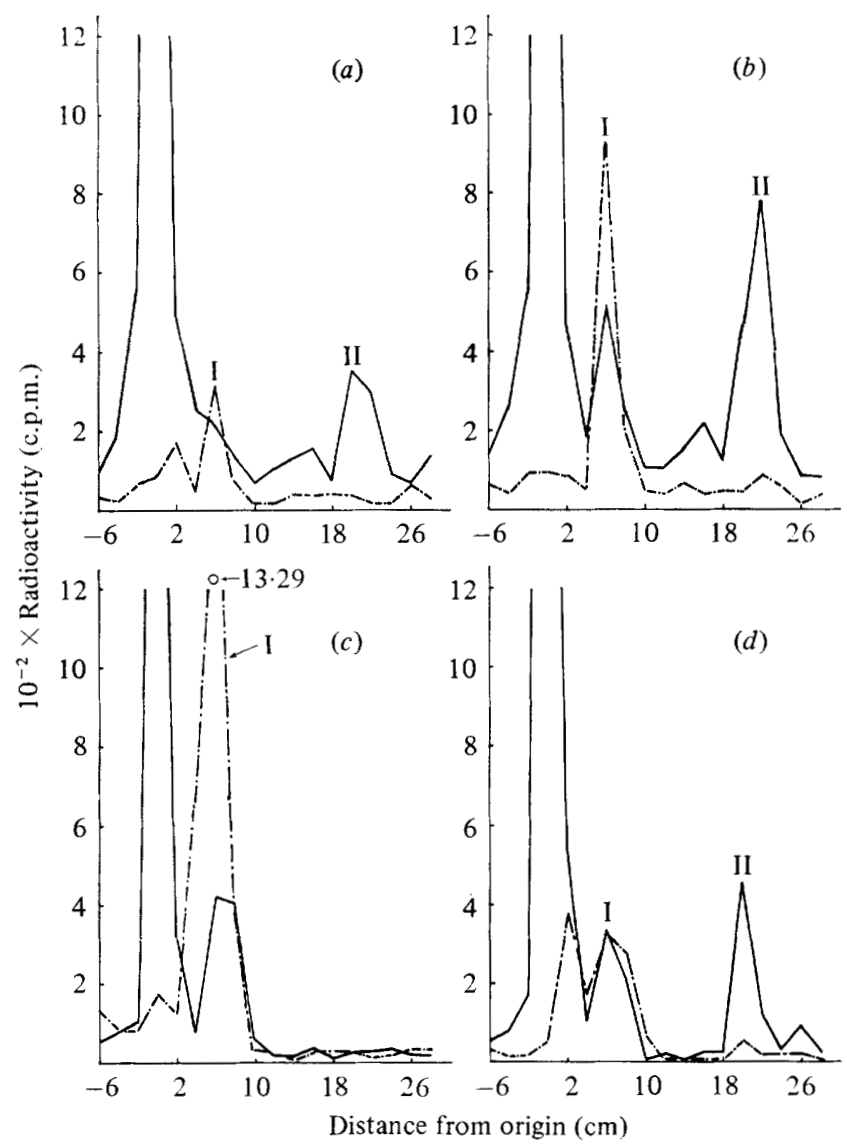

Fig. 2. Distribution of radioactivity in extracts of strains HP41, HP129 and HP83 after incubation with $\alpha$-aminoadipic acid $\left(0.5 \mathrm{mg} \mathrm{ml}^{-1}\right)$ and $\left[{ }^{14} \mathrm{C}\right]$ valine: $(a) \mathrm{HP} 41$, control without $\alpha$-aminoadipic acid treatment; (b) HP41; (c) HP129 (npeW0052); (d) HP83 (npeV006). The extracts were first run in the 'Lilly system', and then the areas corresponding to ACV-tripeptide and 6-aminopenicillanic acid were eluted, oxidized with performic acid and subjected to electrophoresis at $\mathrm{pH} 1.8$ (see Methods):---, radioactivity profile for ACV-tripeptide sample; - - , radioactivity profile for 6-aminopenicillanic acid sample. Peaks $\mathrm{I}$ and II indicate $\mathrm{ACV}-\mathrm{SO}_{3} \mathrm{H}$ and penicillaminic acid, respectively.

to the tripeptide may have been contaminated with other material. In subsequent experiments a two-dimensional separation procedure was employed in an attempt to overcome this problem.

Method B. The tripeptide-like material obtained from an extract of strain HP129 (npeW0052) was isolated following two-dimensional chromatography. The amino acid components of the hydrolysate were separated by electrophoresis at $\mathrm{pH} 1.8$ and $\mathrm{pH} 4.5$. Comparison with various standards indicated the presence of cysteic acid (oxidized during hydrolysis), valine, glycine, $\alpha$-aminoadipic acid and glutamic acid. These results were confirmed by amino acid analysis (Table 5).

In a second experiment with an intracellular extract derived from strain HP129, the peptide was isolated as before after electrophoresis at $\mathrm{pH} 4.5$ and chromatography in the 'Lilly system' (Nash et al., 1974). When a sample of this material was subjected to twodimensional separation using the above systems, a single discrete spot was observed. The remaining material was oxidized with performic acid and a portion of the oxidized material was run at $\mathrm{pH} 1.8,70 \mathrm{~V} \mathrm{~cm}-1$ for $2.25 \mathrm{~h}$ followed by descending chromatography in butanol/acetic acid/water ( $4: 1: 4$, by vol.) for $18 \mathrm{~h}$. This procedure showed the presence of 
Table 4. Distribution of ${ }^{14} \mathrm{C}$ in the sulphonic acids derived from the intracellular extracts of strains after incubation with $\alpha$-aminoadipic acid $\left(0.5 \mathrm{mg} \mathrm{ml}^{-1}\right)$

$\begin{array}{cccc}\text { Strain no. } & \text { npe mutation } & \begin{array}{c}\text { Radioactivity (c.p.m.) in: } \\ \begin{array}{c}\mathrm{ACV}_{\text {(from }} \mathrm{SO}_{3} \mathrm{H} \\ \text { tripeptide) }\end{array}\end{array} & \begin{array}{c}\text { Penicillaminic } \\ \text { acid }\end{array} \\ \text { (from 6APA*) } \\ \text { HP1 } & - & 1443 & 1317 \\ \text { HP83 } & \text { W0052 } & 3297 & 0 \\ & \text { V006 } & 917 & 580 \\ \text { * 6APA, 6-aminopenicillanic acid. }\end{array}$

Table 5. Amino acid analysis of hydrolysed ACV tripeptide-like material from strain HP129

\begin{tabular}{lcc}
\multicolumn{1}{c}{ Amino acid } & $\begin{array}{c}\text { Amount } \\
\text { (nmol) }\end{array}$ & $\begin{array}{c}\text { Molar } \\
\text { ratio* }\end{array}$ \\
Cysteic acid & $29 \cdot 8$ & $2 \cdot 3$ \\
Glutamic acid & $22 \cdot 0$ & $1 \cdot 7$ \\
Glycine & $21 \cdot 5$ & $1 \cdot 7$ \\
Valine & $12 \cdot 8$ & $1 \cdot 0$ \\
\&-Aminoadipic acid & $12 \cdot 5$ & $1 \cdot 0$ \\
\multicolumn{2}{c}{$*$ With respect to valine $(=1 \cdot 0)}$.
\end{tabular}

two components which, in a subsequent separation, co-chromatographed with glutathione sulphonic acid and $\mathrm{ACV}-\mathrm{SO}_{3} \mathrm{H}$.

Glutathione has a similar mobility to the tripeptide at $\mathrm{pH} 4 \cdot 5$, but it runs more slowly in the 'Lilly system'. It is thus possible that the ACV tripeptide-like spot was contaminated with glutathione, although this does not seem likely since the two-dimensional homogeneity check gave a single discrete spot. An alternative suggestion is that disulphide bonds might exist between glutathione and a tripeptide-like substance which remain intact at $\mathrm{pH} 4 \cdot 5$, but which, on performic acid oxidation, yield two sulphonic acid residues that are readily resolved by electrophoresis at $\mathrm{pH} 1.8$ followed by descending chromatography in butanol/ acetic acid/water (4:1:4, by vol.). Unfortunately, when the remaining material was hydrolysed and separated using the amino acid analyser, no measurable peaks were obtained.

A comparison of the results obtained for strain HP41 (a penicillin producer) and strain HP129 (a penicillin non-producer) show a number of interesting features. In every analysis, valine, $\alpha$-aminoadipic acid, cysteine (or cysteic acid) and glycine were present, the first two always in equimolar proportions and the last two at a higher concentration. For strain HP41, the analysis indicated the presence of only these four amino acids, though whether this peptide can be regarded as a simple tetrapeptide is open to question. Analysis of the extract from strain HP129 demonstrated the presence of a fifth amino acid, glutamic acid. The relative concentrations at which these residues were present do not suggest that a pentapeptide is the sole component of the isolated material. The possibility that a disulphide bond exists between ACV-like molecules and glutathione cannot be disregarded. Moreover, although the difference observed between strains HP41 and HP129 may reflect a real difference in the nature of their tripeptide-like material, the method by which the intracellular extracts were prepared and analysed was different and this may have affected the oxidation state of various compounds. It may also have influenced the nature and extent of contaminating substances.

Although these investigations have not demonstrated the existence of a simple ACVtripeptide, as was hoped, it seems likely that the material isolated is in some way involved in penicillin biosynthesis. 
Table 6. Acyl-exchange activity measured by the distribution of radioactivity in penicillin $G$ and penicillin $V$

\begin{tabular}{lcccc}
\multicolumn{1}{c}{$\begin{array}{c}\text { Spe } \\
\text { Strain no. }\end{array}$} & $\begin{array}{c}\text { Penicillin G } \\
\text { (c.p.m.) }\end{array}$ & $\begin{array}{c}\text { Penicillin V } \\
\text { (c.p.m.) }\end{array}$ & Ratio V/G \\
Control (enzyme-free) & - & 1421 & 17 & $0 \cdot 012$ \\
Control (HP74, Lys) & - & 769 & 59 & $0 \cdot 077$ \\
WIS54-1255 & - & 706 & 473 & $0 \cdot 670$ \\
HP16 & - & 1052 & 81 & $0 \cdot 077$ \\
HP41 & - & 851 & 66 & $0 \cdot 078$ \\
HP83 & $V 006$ & 1611 & 28 & $0 \cdot 017$ \\
HP129 & W0052 & 851 & 66 & $0 \cdot 078$ \\
HP149 & X0066 & 838 & 11 & $0 \cdot 013$ \\
HP150 & Y0067 & 935 & 181 & $0 \cdot 190$ \\
HP96 & Y0019 & 548 & 85 & $0 \cdot 160$ \\
HP78 & Z001 & 793 & 51 & $0 \cdot 064$
\end{tabular}

Table 7. Summarized results of acyl-exchange ability and presence or absence of $\alpha$-aminoadipoyl-cysteinyl-valine

\begin{tabular}{|c|c|c|c|}
\hline Strain no. & npe mutation & $\begin{array}{c}\text { Presence of } \\
\text { tripeptide }\end{array}$ & $\begin{array}{l}\text { Acyl-exchange } \\
\text { ability }\end{array}$ \\
\hline HP15 & 一 & + & Not tested \\
\hline HP16 & - & + & + \\
\hline HP20 & 一 & + & Not tested \\
\hline HP41 & 一 & + & + \\
\hline HP74 & - & Not tested & + \\
\hline HP83 & $V 006$ & + & Trace \\
\hline HP129 & W0052 & + & + \\
\hline HP149 & $X 0066$ & 0 & 0 \\
\hline HP96 & $Y 0019$ & 0 & + \\
\hline HP150 & Y0067 & 0 & + \\
\hline HP78 & $Z 001$ & 0 & + \\
\hline
\end{tabular}

\section{Determination of acyl-exchange activity}

The strains assayed for acyl-exchange activity were five Npe mutants, representative of the five complementation groups, parental strain HP16 and strain WIS54-1255, which has a relatively high penicillin yield. Also included was auxotrophic strain HP74; this has a requirement for either lysine or $\alpha$-aminoadipic acid and so is affected at a step in the lysine biosynthetic pathway prior to $\alpha$-aminoadipic acid and thus incapable of elaborating wildtype quantities of penicillin (Goulden \& Chattaway, 1968). The auxotroph was employed as a control, representing a non-producing strain, known not to have a defective acyltransferase. Another control included was an enzyme-free reaction mixture. The distribution of radioactivity between penicillin $G$ and $V$ after 60 min incubation was used as a measure of the acyl-exchanging ability of the strains (Table 6). No increase in the labelling of the penicillin $\mathrm{V}$ peak was observed after longer periods of incubation.

The results of the tripeptide and acyl-exchange investigations are summarized in Table 7.

\section{DISCUSSION}

Relationships between secondary metabolite production and growth morphology have been reported on several occasions (Alikhanian et al., 1959; Blumauerová et al., 1969; Ditchburn et al., 1976; Simpson, 1977). Therefore the effect of changes in colonial morphology on the production of penicillin cannot be ignored. However, in our initial study, morphological mutants, possibly having mutations with pleiotropic effects on antibiotic production, were ignored in the hope of selecting only those mutants impaired in penicillin 
biosynthesis. Similarly, Npe mutants failing to synthesize the yellow pigment chrysogenin were not selected since loss of ability to produce this pigment is often accompanied by loss of penicillin production.

If two strains impaired in the production of a metabolite produce it in normal amounts when grown together, then an accumulated intermediate or intermediates must be able to pass from the site of synthesis in one strain to the site of blockage in the other strain. Three studies using blocked mutants of Penicillium chrysogenum (Bonner, 1947; Sermonti, 1956; Nash et al., 1974) all failed to show co-synthesis, possibly due to the instability of intermediates or their inability to diffuse. The 12 mutants representative of the five complementation groups described in this paper all failed to produce penicillin when grown in all possible pairs.

In complementation studies involving nine mutants of $P$. chrysogenum impaired in penicillin yield, Sermonti (1956) found that the mutations in all but one were at a single genetic locus. The ninth, a partial non-producer, complemented with a representative of the large group and was later located on a separate haploidization group. Sermonti (1959) suggested several explanations for the absence of complementation among the majority of penicillin-less mutants of $P$. chrysogenum of which the most feasible would seem to be (i) a single locus controlling the condensation of the three components of penicillin (cysteine, valine and $\alpha$-aminoadipic acid) or (ii) an exceedingly high mutation rate of one among several loci controlling penicillin biosynthesis.

In studies with Aspergillus nidulans where four complementation groups were identified (Edwards et al., 1974), the existence of a large group containing the majority of mutants was reported. This locus, designated $n p e A$, has also been found to be affected in wild-type strains of Asp. nidulans incapable of synthesizing detectable amounts of penicillin (Cole et al., 1976).

The results presented here demonstrated the existence of a large complementation group, designated $\mathrm{Y}$, containing seven of the 12 mutants tested. This group was assigned to a haploidization group probably analogous to that of Sermonti's group I (I. D. Normansell, G. Holt \& K. D. Macdonald, unpublished results). The locus represented by the mutation npeV006 mapped on a separate linkage group from that on which group $\mathrm{Y}$ was located. Of the other three complementation groups reported here, representatives of groups $\mathrm{W}$ and $\mathrm{Z}$ have been assigned to the same haploidization group as the $Y$ locus, whilst a member of group $X$ has been found to segregate independently of loci V, W and Z. (I. D. Normansell, G. Holt \& K. D. Macdonald, unpublished results). Therefore groups $Y, W$ and $Z$ are situated on one haploidization group, group $\mathrm{X}$ on a second and group $\mathrm{V}$ on a third.

Arnstein \& Morris (1960) first isolated ACV-tripeptide from the mycelium of $P$. chrysogenum. Its similarity to isopenicillin $\mathrm{N}$ and thus to penicillin was recognized when the former was identified by Flynn et al. (1962) and Cole \& Batchelor (1963). The tripeptide has the same optical configuration in Acremonium chrysogenum and P. chrysogenum (Loder \& Abraham, 1971; Adriaens et al., 1975). However, the latter authors suggested the possibility that an 'all L' tripeptide is the precursor of penicillin and of the 'LLD' tripeptide, both of which were excreted. The 'all L' tripeptide has not, however, been isolated from either $A c r$. chrysogenum or $P$. chrysogenum. The separation procedures described in this paper were incapable of distinguishing between optical isomers of ACV.

Nash et al. (1974) found two types of mutants of Acr. chrysogenum lacking the ability to produce detectable amounts of cephalosporin $\mathrm{C}$ - those with, and those without the ability to synthesize the sulphur-containing peptides (including the tripeptide) described by Loder \& Abraham (1971). Adriaens et al. (1975) found LLD tripeptide in a penicillin-producing and in a non-producing strain of $P$. chrysogenum. Our discovery that mutants from two complementation groups producing tripeptide were incapable of yielding significant amounts of antibiotic directed our attention to the final steps in the pathway.

Penicillin acylase was first recognized in mycelial extracts of $P$. chrysogenum by Sakaguchi \& Murao (1950). It hydrolysed penicillin V more rapidly than penicillin $G$ but was inactive 
against penicillin N (Erickson \& Bennett, 1965). More recently, Spencer \& Muang (1970) purified this acylase and demonstrated that it possessed four distinct activities - penicillin acyl-exchange, penicillin acyltransferase, penicillin acylase and phenylacetyl-CoA hydrolase. The four activities were inseparable by their techniques, had the same $\mathrm{pH}$ optimum, were thiol-dependent and were produced at the same growth stage. The authors concluded that the four activities were possessed by a single enzyme. The ability of extracts of $P$. chrysogenum to acylate 6-aminopenicillanic acid has been recognized by a number of workers (Brunner et al., 1968; Spencer, 1968; Gatenbeck \& Brunsberg, 1968; Pruess \& Johnson, 1967).

Peterson \& Wideburg (1960) showed that acyl-exchange reactions could take place between penicillin $\mathrm{V}$ and ${ }^{35} \mathrm{~S}$-labelled penicillin $\mathrm{G}$ in cell-free extracts. These results were confirmed by Pruess \& Johnson (1967) who observed exchange only when thiol compounds were present. The activity was optimal at $\mathrm{pH} 8.0$ and was stimulated by the addition of 6-aminopenicillanic acid. This exchange activity may be regarded as a fifth activity of the enzyme described by Spencer \& Muang (1970). Demain (1974) favours this view.

A comparison of enzyme activities in different strains of $P$. chrysogenum showed that the wild-type strain NRRL 1951 possessed about one-twentieth of the activity (per g dry wt) of WIS51-20F3, a highly developed mutant yielding 200 times more penicillin than NRRL 1951 (Pruess \& Johnson, 1967). In our experiments the exchange reaction with WIS54-1255 went virtually to completion within $60 \mathrm{~min}$, whereas the penicillin-producing derivative of NRRL 1951, strain HP16, only achieved approximately $8 \%$ conversion (Table 6). It is interesting that two mutants, representatives of group $\mathrm{Y}$, were more efficient at performing the exchange reaction than strain HP16.

Members of groups $\mathrm{V}$ and $\mathrm{W}$, which appear to be capable of producing ACV-tripeptide but not penicillin, could be blocked either at some stage in the cyclization of the nucleus or in the acyltransferase terminal reactions. The discovery that strain HP83 (npeV006) possessed only a trace of acyl-exchange activity suggested that this strain was a low penicillin producer because it synthesized either less of the wild-type enzyme or a defective enzyme. Since this enzyme was reported to accept a fairly wide range of substrates it might tolerate a limited amount of change without losing activity completely. A member of group W, however, possessed almost full acyl-exchange activity and may therefore be blocked between the tripeptide and isopenicillin $\mathrm{N}$ or 6-aminopenicillanic acid. It remains to be established which of the last two compounds is the immediate precursor of penicillin. Further work is in progress to establish whether mutants of groups $\mathrm{V}$ and $\mathrm{W}$ produce isopenicillin $\mathrm{N}$.

Members of complementation groups $\mathrm{X}, \mathrm{Y}$ and $\mathrm{Z}$ appear not to be capable of tripeptide synthesis. Mutants of groups $\mathrm{Y}$ and $\mathrm{Z}$ produce an acyl-exchange enzyme whereas a mutant representative of group $X$ had neither the tripeptide-like material nor acyl-exchange activity. The significance of the changes in growth characteristics in mutants of groups $\mathrm{Z}$ and $\mathrm{X}$ (reduced radial colony growth rate and reduced mycelial dry weight, respectively) is unclear.

Investigations of mutants impaired in the production of secondary metabolites can provide valuable information on biosynthetic pathways and regulation. This, in turn, can lead to a more rational approach to screening for improved mutants (Demain, 1973).

The present work has revealed the existence of five loci concerned with penicillin biosynthesis. Biochemical analysis has provided information on the nature of the mutations and these studies provide a basis for future investigations of the genetic regulation of penicillin biosynthesis.

We are particularly grateful to Professor E. P. Abraham (Sir William Dunn School of Pathology, University of Oxford) for his help in providing facilities for some of the biochemical work and to Dr K. D. Macdonald (Microbiological Research Establishment, Porton Down, Salisbury) for his advice and critical reading of the manuscript. We would also like to thank the following for their many and varied contributions: Dr P. J. Bailey 
(Glaxo Laboratories Ltd, Ulverston), Dr R. Fildes (Bristol Myers Co., U.S.A., formerly of Glaxo Laboratories Ltd) and Mr T. A. Savidge (Beecham Pharmaceuticals Ltd).

\section{REFERENCES}

Adriaens, P., Meeschaert, B., Wuyts, W., VANDERHAGHe, H. \& EySSEN, H. (1975). Presence of $\delta$-(L- $\alpha$-aminoadipyl)-L-cysteinyl-D-valine in fermentations of Penicillium chrysogenum. Antimicrobial Agents and Chemotherapy 8, 638-642.

Alderson, T. \& ScoTT, B. R. (1970). The photosensitizing effect of 8-methoxypsoralen on the inactivation and mutation of Aspergillus conidia by near ultraviolet light. Mutation Research 9, 569-578.

Alikhanian, S. I., Mindlin, S. Z., Goldat, S. U. \& Vladimizov, A. V.(1959). Genetics of organisms producing tetracyclines. Annals of the New York Academy of Sciences 81, 914-949.

Arnstein, H. R. V. \& Morris, D. (1960). The structure of a peptide containing $\alpha$-aminoadipic acid, cysteine and valine, present in the mycelium of Penicillium chrysogenum. Biochemical Journal 76, 357-361.

Arnstein, H. R. V., Artman, M., Morris, D. \& ToMs, E. J. (1960). Sulphur-containing amino acids and peptides in the mycelium of Penicillium chrysogenum. Biochemical Journal 76, 353-357.

Backus, M. P. \& Stauffer, J. P. (1955). The production and selection of a family of strains in Penicillium chrysogenum. Mycologia 47, 429463.

Blumauerová, M., MračeK, M., VANDRáčKová, J., Podojil, J., Hošǐ́́leK, Z. \& VANěK, Z. (1969). Regulation of biosynthesis of secondary metabolites. IX. Biosynthetic activity of blocked mutants of Streptomyces aureofaciens. Folia microbiologica 14, 215-225.

BONNER, D. (1947). Studies on the biosynthesis of penicillin. Archives of Biochemistry 13, 1-9.

Brewer, G. A. K. \& JoHnson, M. J. (1953). Activity and properties of para-aminobenzyl penicillin. Applied Microbiology 1, 163-166.

Brownlee, K. A., Loraine, P. K. \& Stephens, J. (1949). The biological assay of penicillin by a modified plate method. Journal of General Microbiology 3, 347-352.

BRUNNER, R., RoHR, M. \& ZINNER, M. (1968). Zur Biosynthese des Penicillins. Hoppe-Seyler's Zeitschrift für physiologische Chemie 349, 95-103.

Caglioti, M. T. \& Sermonti, G. (1956). A study of the genetics of penicillin-producing capacity in Penicillium chrysogenum. Journal of General Microbiology 14, 38-46.

Cole, M. \& Batchelor, F. R. (1963). Aminoadipyl penicillin in penicillin-producing fermentations. Nature, London 198, 383-384.

Cole, D. S, Holt, G. \& Macdonald, K. D. (1976). Relationship of the genetic determination of impaired penicillin production in naturally occurring strains to that in induced mutants of Aspergillus nidulans. Journal of General Microbiology 96, 423-426.
DemaIN, A. L. (1973). Mutation and the production of secondary metabolites. Advances in Applied Microbiology 16, 177-202.

DemaIN, A. L. (1974). Biochemistry of penicillin and cephalosporin fermentations. Lloydia 37, 147-167.

Ditchburn, P., Holt, G. \& Macdonald, K. D. (1976). The genetic location of mutations increasing penicillin yield in Aspergillus nidulans. In Proceedings of the Second International Symposium on the Genetics of Industrial Microorganisms, pp. 213-227. Edited by K. D. Macdonald. London: Academic Press.

Edwards, G. F. St. L., Holt, G. \& Macdonald, K. D. (1974). Mutants of Aspergillus nidulans impaired in penicillin biosynthesis. Journal of General Microbiology 84, 420-422.

Edwards, G. F. ST. L., Normansell, I. D. \& Holt, G. (1975). Benlate-induced haploidization in diploid strains of Aspergillus nidulans and Penicillium chrysogenum. Aspergillus Newsletter 12, 15.

ERICKSON, R. C. \& BenNetT, R. E. (1965). Penicillin acylase activity of Penicillium chrysogenum. Applied Microbiology 13, 738-742.

FlynN, E. H., McCormick, M. H., Stamper, M. C., DeV Aleria, H. \& Godzeski, C. W. (1962). A new natural penicillin from Penicillium chrysogenum. Journal of the American Chemical Society 84, 4594-4595.

Fujisawa, Y., Shirafuji, H., Kida, M., Nara, K., Yoneda, M. \& KanzaKi, T. (1973). New findings on cephalosporin $\mathrm{C}$ biosynthesis. Nature, New Biology 246, 154-155.

Fujisawa, Y., Shirafuji, H. \& KanZaKi, T. (1975a). Deacetylcephalosporin $\mathrm{C}$ formation by cephalosporin C acetyl-hydrolase induced in a Cephalosporium acremonium mutant. Agricultural and Biological Chemistry 39, 1303-1309.

Fujisawa, Y., Shirafuji, H., Kida, M., Nara, K., YonedA, M. \& KANZAKI, T. (1975b). Accumulation of deacetylcephalosporin $\mathrm{C}$ by cephalosporin $\mathrm{C}$ negative mutants of Cephalosporium acremonium. Agricultural and Biological Chemistry 39, 1295-1301.

Gatenbeck, S. \& Brunsberg, U. (1968). Biosynthesis of penicillin. 1. Isolation of a 6aminopenicillanic acid acyltransferase from Penicillium chrysogenum. Acta chemica scandinavica 22, 1059-1061.

Goulden, S. A. \& Chattaway, F. W. (1968). Lysine control of $\alpha$-aminoadipate and penicillin synthesis in Penicillium chrysogenum. Biochemical Journal 110, 55P-56P.

Heilmann, J., Barrellier, J. \& Watzke, E. (1957). Beitrag zur Aminosäurebestimmung auf Papierchromatogrammen. Hoppe-Seyler's Zeitschrift für physiologische Chemie 309, 219-220. 
Hockenhull, D. J. D. (1959). The influence of medium constituents on the biosynthesis of penicillin. Progress in Industrial Microbiology 1, 3-27.

Holt, G. \& Macdonald, K. D. (1968). Penicillin production and its mode of inheritance in Aspergillus nidulans. Antonie van Leeuwenhoek 34, 409-416.

Katz, A. M., Dreyer, W. J. \& Anfinsen, C. B. (1959). Peptide separation by two-dimensional chromatography and electrophoresis. Journal of Biological Chemistry 234, 2897-2900.

LemKe, P. A. \& NASH, C. H. (1972). Mutations that affect antibiotic synthesis by Cephalosporium acremonium. Canadian Journal of Microbiology 18, 255-259.

LoDER, P. B. \& ABRAHAM, E. P. (1971). Isolation and nature of intracellular peptides from a cephalosporin C-producing Cephalosporium sp. Biochemical Journal 123, 471-476.

Macdonald, K. D. (1966). Differences in diploids synthesised between the same parental strains of Penicillium chrysogenum. Antonie van Leeuwenhoek 32, 431-441.

Macdonald, K. D. \& Holt, G. (1976). Genetics of biosynthesis and over-production of penicillin. Science Progress, Oxford 63, 547-573.

Macdonald, K. D., Hutchinson, J. M. \& Gillett, W. A. (1963a). Isolation of auxotrophs of Penicillium chrysogenum and their penicillin yields. Journal of General Microbiology 33, 365-374.

Macdonald, K. D., Hutchinson, J. M. \& GilletT, W. A. $(1963 b)$. Formation and segregation of heterozygous diploids between a wild-type strain and derivatives of high penicillin yield in Penicillium chrysogenum. Journal of General Microbiology 33, 385-394.

Macdonald, K. D., Hutchinson, J. M. \& Gillett W. A. (1965). Heterozygous diploids of Penicillium chrysogenum and their segregation patterns. Genetica 36, 378-397.

Merrick, M. J. \& Caten, C. E. (1975). The design of fermentation and biological assay procedures for assessment of penicillin production in populations of Aspergillus nidulans. Journal of Applied Bacteriology 38, 121-131.

Nash, C. H., de la Higuera, N., Neuss, N. \& LEMKe, P. A. (1974). Application of biochemical genetics to the biosynthesis of $\beta$-lactam antibiotics. Developments in Industrial Microbiology 15, 114-123.

Peterson, W. H. \& Wideburg, N. E. (1960). Enzymatic interconversion of penicillins $\mathrm{G}$ and $\mathrm{V}$. In Proceedings of the 4th International Congress of Biochemistry, Vienna, vol. 15, p. 136. London: Pergamon.

Pontecorvo, G., Roper, J. A., Hemmons, L. M., Macdonald, K. D. \& Bufton, A. W. J. (1953). The genetics of Aspergillus nidulans. Advances in Genetics 5, 141-238.

Pruess, D. L. \& Johnson, M. J. (1967). Penicillin acyltransferase in Penicillium chrysogenum. Journal of Bacteriology 94, 1502-1508.

Raper, K. B. \& Alexander, D. F. (1945). Penicillin V. Mycological aspects of penicillin production. Journal of the Elisha Mitchell Scientific Society 61, 74-113.

SaKaguchi, K. \& Murao, S. (1950). A preliminary report on a new enzyme, penicillin-amidase. Journal of the Agricultural Chemical Society of Japan 23, 411.

SERmonti, G. (1956). Complementary genes which affect penicillin yields. Journal of General Microbiology 15, 599-608.

SERMONTI, G. (1959). Genetics of penicillin production. Annals of the New York Academy of Sciences 81, 950-973.

SIMPSON, I. N. (1977). A quantitative investigation of the genetics of penicillin production in mutation selected lines of Aspergillus nidulans. Ph.D. thesis, University of Birmingham.

Smith, B., Warren, S. C., Newton, G. G. F. \& Abraham, E. P. (1967). Biosynthesis of penicillin $\mathrm{N}$ and cephalosporin $\mathrm{C}$. Antibiotic production and other features of the metabolism of a Cephalosporium sp. Biochemical Journal 103, 877-890.

Spencer, B. (1968). The biosynthesis of penicillins: acylation of 6-aminopenicillanic acid. Biochemical and Biophysical Research Communications 31, 170-175.

SPENCER, B. \& MuANG, C. (1970). Multiple activities of penicillin acyltransferase of Penicillium chrysogenum. Biochemical Journal 188, 29P-30P.

Yost, H. T., ChalefF, R. S. \& FinerTy, J. P. (1967). Induction of mitotic recombination in Saccharomyces cerevisiae by ethylmethane sulphonate. Nature, London 215, 660-661. 